J. Indian Chem. Soc.,

Vol. 78, October-December 2001, pp. 627-633

\title{
Sonochemistry : Past, present and future
}

\author{
Suresh C. Ameta*, Pinki B. Punjabi, Harish Swarnkar, Neeru Chhabra and Madhu Jain \\ Department of Chemistry, College of Science, Sukhadia University, Udaipur-313001, India
}

Manuscript received 2 April 2001

The term ultrasound is very common in reference of animal communications (bats, dog whistles), medical diagnosis (foetal scanning, treatment of muscle strains), cleaning and drilling of teeth, plastics and metals welding and underwater ranging (SONAR), etc. Ultrasound is defined as sound of a frequency, which is beyond human hearing, i.e. above $16 \mathrm{kHz}$. It has been recently reported that chemical reactivity of a system increases on irradiating it with power ultrasound. The study of effects of ultrasound on chemical reactivity is termed as sonochemistry.

Many sonicators are useful for the production of ultrasound. The important ones are : ultrasonic cleaning bath, ultrasonic probe system, the cuphorn system, the flow cell system, the submersible transducer assembly, the whistle reactor, the tube reactor and ultrasonic interferometer, etc. There are two distinct ranges of ultrasound : diagnostic (for physical measurements) and power (to influence chemical reactivity). After the Titanic disaster of 1912, it was suggested that the distance of an iceberg from a ship could be easily estimated from the time lapse between emitting a sound from a ship and receiving an echo from the iceberg. Thus the pulse/echo ranging technique or diagnostic ultrasound developed for the location of submarines and later, this technique led to SONAR (SOund, Navigation $A$ nd Ranging) and flaw detection in metals and other materials. Diagnostic ultrasound can be used for chemical analysis particularly for remote sensing in flow system.

Sir John Thornycroft and Sidney Barby characterized an effect called cavitation through which power ultrasound influences the chemical reactivity of a system. It is known that sound is transmitted through a fluid as a wave consisting of alternating comperssion and rarefaction cycles. This creates an acoustic pressure in the medium, which varies with time. This acoustic intensity is the energy transmitted through 1 $\mathrm{m}^{2}$ of fluid per unit time, which will vary with distance from its source due to attenuation caused by viscous forces and resulting in heating of the liquid.

Sonication causes enhanced molecular motion and this leads to very efficient mass transfer and mixing and so can enhance many chemical reactions. If the negative pressures during the rarefaction phase of the waves are sufficiently large, then the liquid will be 'torn apart', which results in the formation of voids or bubbles - this process is known as cavitation. This may occur at pressures much less than those required overcoming the tensile strength of a liquid since there are always minute dust particles or dissolved gases present, which act as nucleating sites. During its growth, dissolved gases and/or solvent vapour may diffuse into the bubble. Sonication is very effective for degassification as any dissolved gases or gas bubbles will not easily collapse in the compression cycle and it will continue to grow on further rarefaction cycles, filling with more gas and finally floating to the surface. Since the rarefaction cycles are taking place very rapidly, and hence, the bubbles grow so quickly that degassing appears to occur almost instantaneously.

In a cavitating system, three different zones can be identified : (i) the bulk liquid, in which no primary sonochemical activity takes place, (ii) the center of the bubble, where the harsh conditions cause reactions in vapours and gases, and (iii) the interfacial region, where there are large variations in temperature and pressure gradients and also very high shear gradients due to shock waves and motion of solvent molecules around the collapsing bubbles.

Many factors affect cavitation. Most of the sonochemical work has been done having frequencies around $20-50 \mathrm{kHz}$. The sonochemical effects is very less at higher frequencies because then the bubbles has limited time to grow and collapse. The sonochemical activity rises with increasing ultrasound intensity but this efficiency falls in many reactions above a particular optimum intensity. Highly soluble gases reduce the cavitation threshold of a liquid but these also lead to greater amounts of gases entering the bubbles; thus, resulting in a 'cushioning' of the collapse and as a consequence, reducing sonochemical activity. Higher sonochemical activity is obtained in solvents with low vapour pressures. Solvent with high densities, surface tensions and viscosities generally have a higher threshold for cavitation but more harsh conditions appear once cavitation begins. A very large sonication effect has been observed at lower temperatures. 
Ultrasonic homogenization and emulsification can be applied in the synthesis of polymers by emulsion and suspension polymerization. It can also be used in the food industry for the processing of tomato ketchup, etc.

\section{Synthetic sonochemical reactions}

Ultrasound gives a way of energizing a chemical system along with the more classical methods such as, thermal, photochemical and electrochemical. Ultrasound opens up new synthetic routes for synthetic organic chemistry, improves regio- and stereoselectivity of reactions, increases the ability to manipulate selected functional groups without affecting other groups. The application of ultrasound will increase the rate of heterogeneous reactions by aiding mass transfer and reactions involving metals by cleaning and activating their surfaces. Many sonochemical reactions have been proposed. Some of these are described below.

\section{Reduction :}

The use of ultrasound favoured the reduction of aromatic hydrocarbons to their radical anions by alkali metals. The ultrasound cleans the surface of the metal by removing the layer of metal hydroxide present on it and breaks up the pieces of metals. A recent example of one electron reduction $^{1}$ is

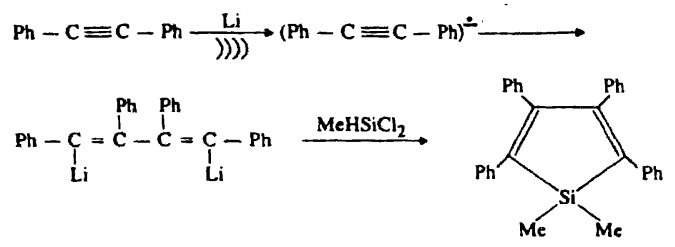

Torok et $a l{ }^{2}$ reported sonochemical enantioselective hydrogenation of ethyl pyruvate over platinum catalyst.

\section{Alkylation :}

Ultrasound enhances the rate of these reactions and improves the yields and purity of products. A very useful alkylation reactions is the preparation of diazacorand ${ }^{3}$.<smiles>C1COCCOCCNCCOCCOCCN1</smiles>

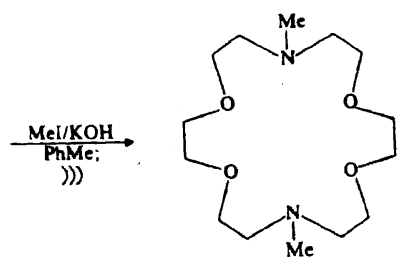

Ester hydrolysis :

Methyl 2,4-dimethylbenzoate on alkaline hydrolysis gives 2,4-dimethylbenzoic acid ${ }^{4}$. The following results show the beneficial use of ultrasound in this reaction :
Time of reaction, $\mathrm{min}$.

Condition

90

10

60

Yield\% of 2,4-dimethylbenzoic acid

Reflux Ultrasound Ultrasound

The use of ultrasound is also advantageous in the hydrolysis of naturally occurring oils and waxes and in this manner the amount of side-products is reduced. Time can be reduced for the completion of reaction by using ultrasound. Ultrasound reduces the particle size of the oil droplets, which is an essential part of emulsification.

\section{Generation of reactive intermediates :}

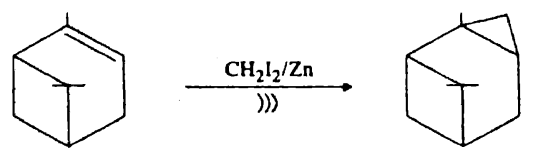

In this dehalogenation reaction, carbene is formed in the presence of zinc ${ }^{5}$. But if this reaction is carried out with ultrasound, it cleans the surface of the zinc, transports reagents to its surface and products away from the surface and generates smaller zinc particles.

\section{Diels-Alder reaction :}

This reaction does not involve single electron transfer process. Lee and Snyder ${ }^{6,7}$ reported the appreciable effect of ultrasound on the rate of the Diels-Alder reaction.<smiles>C=CC1=CCCCC1</smiles>

This reaction synthesizes abietanoid pigments, which are responsible for the biological activity of the Chinese traditional medicine Dan Shen. Under sonication of the reaction mixture, the yields of the products increase.<smiles>O=C1C=CC(=O)O1</smiles><smiles></smiles>

Low $^{8}$ examined the reaction of anthracene with maleic anhydride in toluene. The reaction was completed within 4 $\mathrm{h}$ when a direct immersion microtip probe was used. The 
equivalent thermal reaction is very slow than the sonochemical reaction and was only $11 \%$ complete after the same period of time.

Sonochemical generation of organoiron complexes :

$\pi$-Allyltricarbonyliron lactone complexes are intermediates, which will further synthesize cyclic lactones 9,10 and lactams ${ }^{11}$. The yields of ferrilactone complex obtained from the thermal reaction with $\mathrm{Fe}(\mathrm{CO})_{4}$. THF and the sonochemical reaction with $\mathrm{Fe}_{2}(\mathrm{CO})_{9}$ in benzene are compared ${ }^{12}$.
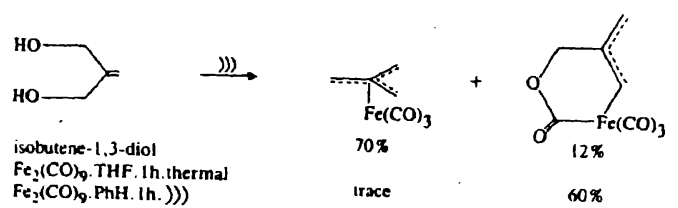

\section{Barbier reaction :}

Improved Barbier reaction involves the reaction of a ketone with alkyl halide in presence of lithium to give the corresponding alcohol with introduction of the alkyl group on carbon of carbonyl group ${ }^{13}$.

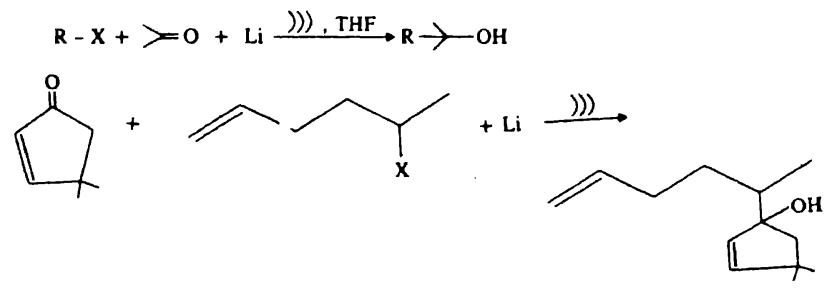

Unusual Barbier reaction was also reported, where it proceeds in presence of zinc ${ }^{14}$.

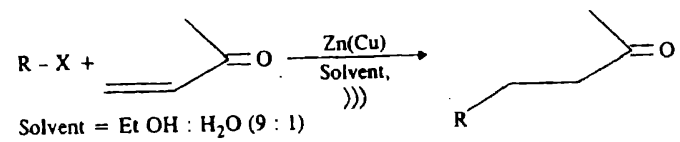

Barbier reaction was modified and some interesting results were obtained depending on the nature of halogen in alkyl halide. Ketone is the major product on using alkyl chloride, while no ketone was obtained in presence of alkyl iodide, rather benzil was formed with a yield of $40 \%{ }^{15}$.

$\mathrm{Ph}-\mathrm{COOLi}+\mathrm{n}-\mathrm{BuCl}+2 \mathrm{Li} \frac{))), \mathrm{THF}}{45 \mathrm{~min} .} \mathrm{Ph} \mathrm{COn}-\mathrm{Bu}$

$\mathrm{PhCOOLi}+\mathrm{n}-\mathrm{Bul}+2 \mathrm{Li} \stackrel{20 \mathrm{kH}_{\mathrm{z}}}{\longrightarrow} \mathrm{PhCOnBu}+\mathrm{PhCOCOPh}$

$0 \% \quad 40 \%$

\section{Photochemistry with ultrasound:}

Photochemistry can be carried out in the presence of $\mathrm{TiO}_{2}$ where a chemical reaction can be initiated by substrate absorption onto a UV-activated surface, e.g. oxidation of sul- fides to sulfones and sulfoxides ${ }^{16}$. The dechlorination ${ }^{17}$ of pentachlorophenol in the presence of $0.2 \% \mathrm{TiO}_{2}$ is very efficient in UV-radiation. When ultrasound is used in conjunction with this, the rate of photolytic dechlorination is enhanced. This is because sonochemistry promotes the surface cleaning, particle size reduction and increase mass transfer to the powder surface.

\section{Miscellaneous reaction :}

Ketones on reductive deoxygenation gives alkenes by low valent titanium compounds. But in this case, the reaction will take place at much milder conditions, if ultrasound is used ${ }^{18}$.

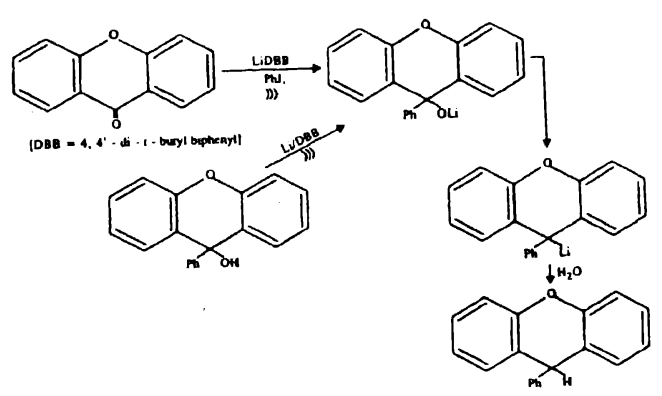

Ultrasound can be used to initiate the formation of Grignard reagents. Magnesium can reduce anthracene under the influence of ultrasound ${ }^{19}$.

$$
\mathrm{Ph}-\mathrm{CH}=\mathrm{CH}-\mathrm{CH}_{2}-\mathrm{Cl}+\mathrm{Bu}_{3} \mathrm{SnCl} \longrightarrow \mathrm{Ph}-\underset{100 \% \text { isolated yield }}{\mathrm{CH}=\mathrm{CH}-\mathrm{CH}_{2}-\mathrm{SnBu}_{3}}
$$

The above reaction of the formation of allylstannanes from allyl halide and stannyl halide will give very low yield. However, if the same reaction is done in the presence of magnesium and ultrasound, the high yield and purity of the product will be obtained, which is synthetically very important ${ }^{20}$.

The generation of perfluoroalkyl zinc halides ${ }^{21}$, and facilitating the Reformatsky reaction ${ }^{22}$ are the example, in which the reaction will not take place in the absence of ultrasound ${ }^{23}$. Luche et al. ${ }^{24}$ initiated to apply the zinc-copper coupled derived reagents, in synthetic organic chemistry using ultrasound. A strong evidence has been proposed in favour of single electron transfer in these reactions. Ultrasound enables zinc and acetic acid to reduce carbon-carbon double bonds of unsaturated esters and quinones ${ }^{25}$. The reduction of diarylketones by zinc in presence of aluminium trichloride leads to reductive coupling ${ }^{26}$.

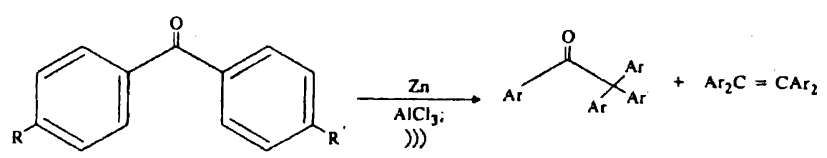

Ultrasound can be utilized to active platinum ${ }^{27}$, palla$\operatorname{dium}^{28}$ and nickel ${ }^{29}$. The activation of nickel of ultrasound 
is recently reported in the hydrogenolysis of N-N bond of hydrazines ${ }^{30}$ and in catalyzing the hydrosilylation of alkenes $^{31}$. Raney nickel modified by interaction with tartaric acid and sodium bromide is transformed into an enantioselective catalyst by the application of ultrasound ${ }^{32}$, which can reduce $\beta$-ketoesters and $\beta$-diketones with high enantioselectivity. These results provide a method that will quite effectively compete with enzymatic methods.

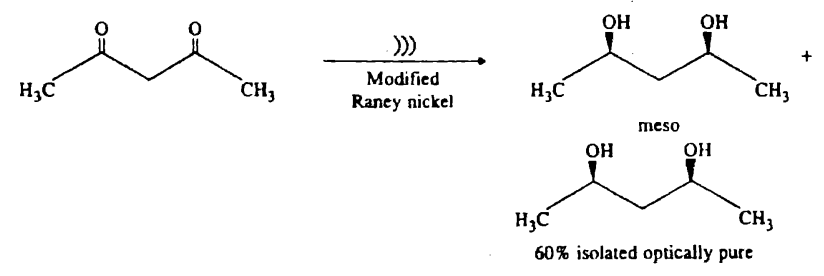

There are some reactions, which in the presence of ultrasound do not involve single electron transfer processes. For example, conversion of aryldiazonium salts to aryl ethers ${ }^{33}$, reaction of sulfonyl azides with alkenes ${ }^{34}$, generation of ketones $^{35}$ and the reduction of esters by zinc borohydride ${ }^{36}$.

Bhatkhande and Samant ${ }^{37}$ observed ultrasonic assisted PTC.catalyzed saponification of vegetable oils using aqueous alkali. Sonochemical degradation of ethylbenzene in aqueous solution was studied by Visscher et al. ${ }^{38}$. Drijuvers et al. ${ }^{39}$ studied organic intermediates in sonolysis of chlorobenzene in aqueous solution. Petrier et al. ${ }^{40}$ reported ultrasound and environment sonochemical destruction of chloroaromatic derivatives. Gaplovsky et al ${ }^{41}$ reported the effects of ultrasound on the photopinacolization of benzophenone. Ultrasound assisted heterogeneous permanganate oxidations were studied by Meriarova et al. ${ }^{42}$. Under sonic conditions, the reductive dehalogenation of $\alpha$-haloketones with zinc in presence of ammonium salts was studied by Rama et $a l .{ }^{43}$. Lorimer et $a l^{44}$ reported the dye effluent decolourization using ultrasonically assisted electro-oxidation. Nagata et al. ${ }^{45}$ reported sonochemical degradation of chlorophenols in water. Rong et al. ${ }^{46}$ studied simple quantification of ultrasonic intensity using aqueous solution of phenolphthalein. Mizukoshi et al. ${ }^{47}$ studied the role of surfactants in the preparation of platinum nanoparticles by sonochemical reduction of the $\mathrm{Pt}^{\mathrm{IV}}$ ions.

\section{Polymers}

There are various fields, where ultrasound is beneficial in the preparation of polymeric materials. Under sonochemical conditions several synthetic methods are accelerated but the greatest effects are in the molecular weight distributions of the resulting polymers. Pethrick ${ }^{48}$ reviewed that high fre- quency ultrasound in the range of $1-10 \mathrm{MHz}$ is applied to the determination of structure and conformation of polymers, while low frequency ultrasound provides information on both polymerization and depolymerization.

The modification of exciting polymers into new materials is a degradation process. Its mechanism is described as the polymer chain being caught in the rapid flow of solvent molecules about collapsing and exploded cavitation bubbles and being subjected to extremely large shear forces. The rate and extent of degradation may be maximized by saturating the polymer solution with gas, employing a gas with a low solubility, using a solvent with a low vapour pressure, reducing the experimental temperature and insonation frequency, increasing the intensity of irradiation and decreasing the solution concentration. Thermal degradation produces cleavage in a random process while in ultrasonic degradation cleavage occurs preferentially near the middle of the chain. Melville and Murray ${ }^{49}$ showed the presence of radical intermediates in the degradation.

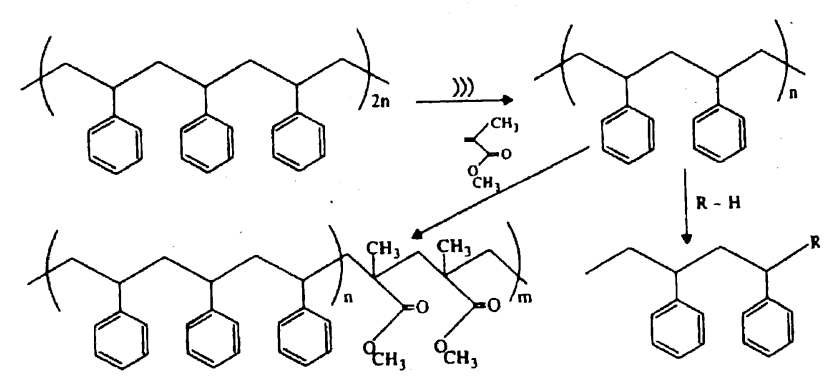

Emulsion or suspension polymerization is another process for preparing polymers ${ }^{50}$. Lorimer et al ${ }^{51}$ compared styrene polymerization carried out in the presence and absence of ultrasound from a high intensity horn. They observed that the decomposition of potassium persulfate was accelerated and which in turn, increased the rate of polymerization together with the production of more stable emulsions.

Leboun and Porte ${ }^{52}$ illustrated the ring opening reactions of octamethyltetrasiloxane to poly(dimethylsiloxane) (PDMS) catalyzed by sulfuric acid.

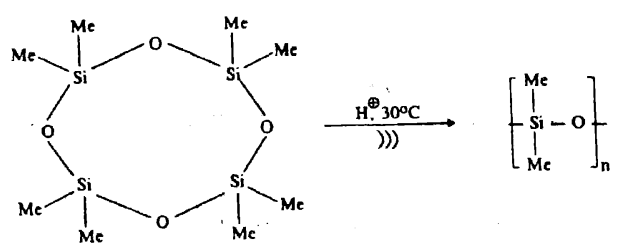

This is the base material of the large number of silicon products. 
Ameta et al. : Sonochemistry : Past, present and future

Ziegler-Natta polymerization :

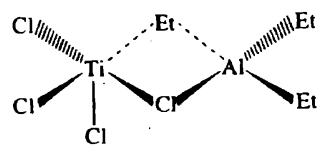

The sonicated reactions gave yields of 56 and $24 \%$ at 60 and $30^{\circ}$, respectively, while in the absence of ultrasound mere 20 and $\approx 5 \%$ yields were observed. This is probably due to efficient mixing and faster mass transfer of monomer to the reactive site on the surface of catalyst on sonication. The particle size may reduce during sonication and as a consequence, increases the active area of the catalyst.

Polyorganosilanes are photoactive and photoconductive and used as photoresists. Ultrasound has been applied in the coupling of chlorosilanes, $\mathrm{R}_{3} \mathrm{SiCl}$ over sonicated lithium metal to give $\mathrm{R}_{3} \mathrm{SiSiR}_{3}{ }^{53}$. This work has been extended to use $\mathrm{R}_{2} \mathrm{SiCl}_{2}$ to give polymeric material.
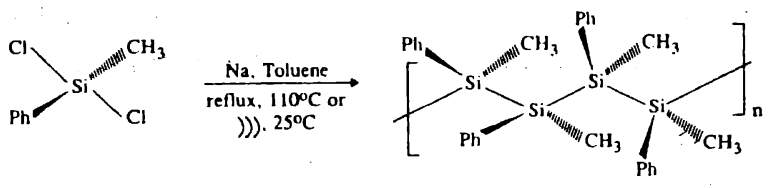

\section{Ultrasound in heterogeneous catalysis}

The use of ultrasound in heterogeneous catalysis enhances the reaction rate. This effect may lead to better reactivity of solid reagents by removal of passive surface coatings, by creation of surface defects, which may lead to reactive centres, by reduction of particle size; thus, increasing the reactive surface area and by improvement in mass transport. The effects of ultrasound in three areas are considered.

\section{Catalyst/reagent preparation :}

It has been observed that the use of ultrasound in the preparation of solid catalyst leads to improve catalytic activity in comparison with the catalyst by chemical methods using only mechanical agitation. The surface area of platinum black, produced in the presence of ultrasound increases to $62 \%$ and magnetic susceptibility also increase upto $98 \%$. It is because that amount of atomic phase present increases, which shows the more catalytic activity than crystalline metal.

Ultrasound is very effective during the crystallization process. This is due to an increase in the nucleation rate caused by the dispersion of crystallization centres throughout the medium. Thus sonication of preformed platinum blacks, leads to a $38 \%$ reduction in surface area and a $50 \%$ increase in crystal size.

The use of ultrasound during the precipitation of a mixed chromium-molybdenum catalyst for the oxidation of metha- nol to formaldehyde ${ }^{54}$ gave catalyst with increased specific area, which led to increased catalytic activity. But if the ultrasound is applied after precipitation, it was led to agglomeration, surface area reduction and loss of activity ${ }^{55}$.

Ranganathan et al. ${ }^{56}$ reported that sonication for one hour of aqueous suspensions of various metal oxide $\left(\mathrm{Cr}_{2} \mathrm{O}_{3}\right.$, $\mathrm{MnO}_{2}, \mathrm{Co}_{2} \mathrm{O}_{3}$ ) and alumina prior to drying and calcination yielded catalyst with higher dispersity of metal oxide and higher activity in the decomposition of hydrogen peroxide.

\section{Catalyst/reagent activation :}

For hydrogenation of alkenes, ordinary $5 \mu$ nickel powder is inactive, while on sonication of the nickel suspended in toluene leads to activation. Nickel presonicated for one hour increases the initial rate of hydrogenation to a maximum but as the period of sonication was increased, the rate decreases. Scanning electron microscopy (SEM) shows that particle size is not changed during sonication; however, surface morphology is changed. The surface is crystalline initially, but after sonication it becomes smooth. On prolong sonication, there is an increase in agglomeration, which may decrease the rate of hydrogenation.

On the activation process, Auger Electron Spectroscopy (AES) reveals that initially the nickel powder is coated in a thick oxide layer extends to a depth of $25 \mathrm{~nm}$. Most of the oxide layer had been removed after sonication for an hour.

\section{Ultrasound during catalysis :}

During catalysis ultrasound give improvements in mass transport, rate of production and renewal of active sites and the desorption of products and poisons from the catalyst surface.

\section{Organometallic reactions}

Organometallic processes promoted by ultrasound can be studied in two parts ${ }^{57}$.

Stoichiometric reactions of group I metals with halosilanes:

$$
\begin{array}{ll}
\left.\left.\mathrm{R}_{3} \mathrm{MX}+\mathrm{Li} \longrightarrow\right)\right) & \mathrm{R}_{3} \mathrm{M}-\mathrm{MR}_{3}>85 \% \\
(\mathrm{M}=\mathrm{C}, \mathrm{Si}, \mathrm{Ge}, \mathrm{Sn}) & \mathrm{R}=\text { alkyl, aryl or } \mathrm{H}
\end{array}
$$

A variety of dichlorosilanes on reduction with lithium, with small groups, silylenes such as $\mathrm{Me}_{2} \mathrm{Si}, \mathrm{Et}_{2} \mathrm{Si}$ and $\mathrm{Ph}_{2} \mathrm{Si}$ were not produced, however, when larger groups are placed on silicon, silylene intermediates are formed.

$$
\mathrm{RR}^{\prime} \mathrm{SiCl}_{2}+\mathrm{Li}+\mathrm{Et}_{3} \mathrm{Si}_{-} \mathrm{H} \stackrel{\text { ))) }}{\longrightarrow} \mathrm{Et}_{3} \mathrm{Si}-\mathrm{SiRR}^{\prime} \mathrm{H}+\mathrm{RR}^{\prime} \mathrm{HSi}-\mathrm{SiRR}^{\prime} \mathrm{H}
$$

As the size of organic substituents on generating silylenes from dihalosilanes increases, the percentage yield of product (A) increases. This can be explained on the basis that the bulky groups inhibit intermolecular coupling providing 
sufficient time for $\alpha$-elimination.

Change in the metal will lead to a change in yields of products. In this case, if lithium, sodium and potassium are used, the percentage yield of product $(\mathrm{C})$ decreases and product (D) increases, respectively.

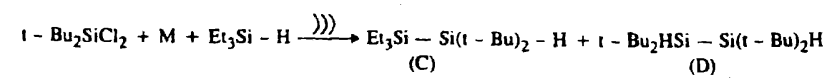

If we go down in the group of halogens, the percentage yield of product $(\mathrm{E})$ decreases and that of product $(\mathrm{F})$ increases.

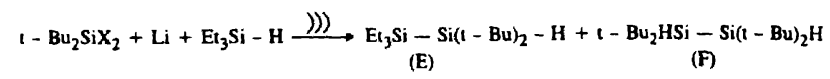

It was proved experimentally that in some cases a 'silylenoid' was formed as an intermediate.

Transition metal catalyzed reactions of silanes:

It was demonstrated that platinum on carbon catalyze hydrosilation.

$$
\mathrm{R}_{3} \mathrm{Si}-\mathrm{H}+>\mathrm{C}=\mathrm{C}\left\langle+\mathrm{Pt} / \mathrm{C} \stackrel{100-300^{\circ}}{\longrightarrow} \mathrm{R}_{3} \mathrm{Si}-\underset{\mathrm{C}}{\mathrm{C}}-\underset{\mathrm{C}}{\mathrm{C}}-\mathrm{H}\right.
$$

However, if ultrasound is used, high yield of product was obtained and by distilling off the products, catalyst may also be reused ${ }^{27}$.

$$
\begin{aligned}
& \mathrm{R}_{3} \mathrm{Si}-\mathrm{H}+>\mathrm{C}=\mathrm{C}\left\langle+\mathrm{Pt} / \mathrm{C} \frac{\partial))}{30^{n}-1 \mathrm{~h}} \rightarrow-\underset{\mathrm{R}_{3} \mathrm{Si}}{\mathrm{C}}-\underset{\mathrm{H}}{\mathrm{C}}-\right. \\
& \left(\mathrm{R}_{3}=\mathrm{Cl}_{3}: \mathrm{Cl}_{2} \mathrm{Me}:\left(\mathrm{E}(\mathrm{O})_{3} ; \mathrm{Et}_{3}\right)\right.
\end{aligned}
$$

Boudjouk and Hauck ${ }^{58}$ examined alkynes by this reaction.

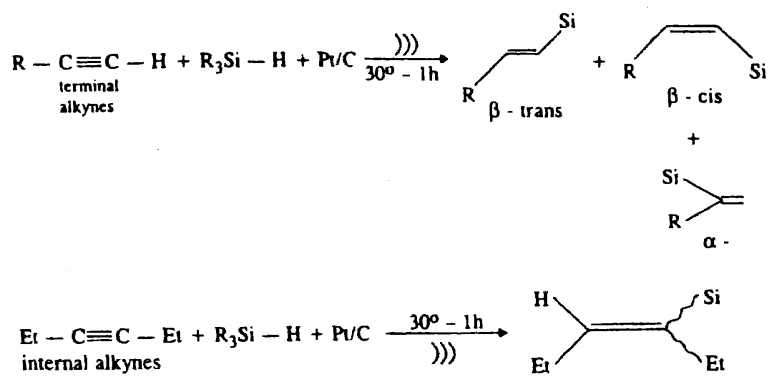

If nickel powder, freshly prepared from nickel halide and lithium in the presence of ultrasonic waves, is used, it catalyzes hydrosilylation very efficiently. In the absence of an olefin, this activated form of nickel will catalyze the dehydrogeneation coupling of silicon hydrides to form Si-Si bond ${ }^{31}$.

$$
2 \mathrm{Ph}_{2} \mathrm{SiH}_{2}+\mathrm{Ni}+\mathrm{PPh}_{3} \longrightarrow \underset{45 \%}{\longrightarrow} \mathrm{Ph}_{2} \mathrm{HSi}-\mathrm{SiH} \mathrm{Ph}_{2}
$$

\section{Future prospects}

Ultrasound has certain advantages in electrochemistry as it keeps electrodes clean and degasses electrode surface ${ }^{59}$. Sonochemical process will replace current methodology in polymer synthesis. Ultrasound can produce many polymers without the need of initiators or emulsifiers, etc. Del Campo et al $^{60}$ studied low temperature sonoelectrochemical processes : mass transport and cavitation effects of $20 \mathrm{kHz}$ ultrasound in liquid ammonia. Masti et al. ${ }^{61}$ observed room temperature sonoelectrochemical synthesis of molybdenum sulfide. Low power ultrasonic irradiation of media assists in the rate of growth and yield of algal cells ${ }^{62}$. A combination of photochemistry with sonochemistry has also been used for the treatment of waste waters ${ }^{17}$. Patent issued in the sonochemical synthesis of 1 -aminoanthraquinone reflects the growing interest in the field ${ }^{63}$. Sonochemistry is a developing field with a number of such frontiers and a much wider range of applications will come out in the years to come. Recently, the buckyball fullerene has also been synthesized, utilizing a sonochemical route ${ }^{64}$. Petrier and Francony ${ }^{65}$ studied incidence of wave frequency on the reaction rates during ultrasonic wastewater treatment.

\section{References}

1. P. Boudjouk and B. H. Han, J. Catal., 1983, 79, 489.

2. B. Torok, K. Felfoldi, G. Szakonyi, K. Balazsik and M. Bartok, Catal. Lett., 1997, 4, 301.

3. J. Jurczak and R. Ostaszewski, Tetrahedron Lett., 1998, 29. 959.

4. S. Moon, L. Duchin and J. V. Cooney, Tetrahedron Lett., 1979, 3917.

5. O. Repic and S. Vogt, Tetrahedron Lett., 1982, 23, 2729.

6. J. Lee and J. K. Snyder, J. Am. Chem. Soc., 1989, 111, 1522.

7. J. Lee, H. S. Mei and J. K. Snyder, J. Org. Chem., 1990, 55, 5013.

8. C. M. R. Low in "Current Trends in Sonochemistry", ed. G. J. Price, Royal Soc. Chem., Cambridge, 1992, pp. 66-67.

9. S. V. Ley, Phil. Trans. R. Soc. London, Ser. A, 1988, 326, 663.

10. R. Aumann, H. Ring, C. Kruger and R. Goddard, Chem. Ber., 1979, 112.

11. S. T. Hodgson, D. M. Hollinshead, S. V. Ley, C. M. R. Low and D. J. Williams, J. Chem. Soc., Perkin Trans. 1, 1985, 2375.

12. R. W. Bates, D. Diez-Martin, W. J. Kerr, J. G. Knight, S. V. Ley and A. Sakellaridis, Tetrahedron, 1990, 46, 4063.

13. N. F. Scilly, J. Chem. Soc., Perkin Trans. 1, 1972, 1655.

14. C. Dupuy, C. Petrier, C. Allavena and J. L. Luche, Tetrahedron Lett., 1986, 27, 3149.

15. J. C. de Souza Barboza, J. L. Luche and C. Petrier, Tetrahedron Lett., 1987, 28, 2013.

16. R. S. Davidson and J. E. Pratt, Tetrahedron Lett., 1983, 24. 5903.

17. T. J. Mason in "Current Trends in Sonochemistry", ed. G. J. Price, Royal Soc. Chem., Cambridge, 1992. 
Ameta et al. : Sonochemistry : Past, present and future

18. S. K. Nayak and A. Banerji, J. Org. Chem.. 1991, 56, 1940.

19. W. Oppolzer and P. Schneider, Tetrahedron Lett., 1984, 25, 3305.

20. Y. Naruta, Y. Nishagaichi and K. Maruyama,Chem. Lett., 1968, 1957.

21. T. Kitazume and N. Ishikawa, J. Am. Chem. Soc., 1985, 107, 5186.

22. R. W. Land and B. Schaub, Tetrahedron Lett., 1988, 29, 2943.

23. T. Kitazume, Synthesis, 1986, 855.

24. J. L. Luche, A. Allavena, C. Petrier and C. Dupuy, Tetrahedron Lett., 1988, 29, 5373.

25. A. P. Marchand and G. M. Reddy, Synthesis, 1991, 198.

26. R. Sato, T. Nagaoka and M. Saito, Tetrahedron Lett., 1990, 31 , 4165 .

27. B. H. Han and P. Boudjouk, Organometallics, 1983, 2, 769.

28. K. Imi, K. Imai and K. Utimoto, Tetrahedron Lett., 1987, 28 . 3127.

29. K. J. Moulton, S. Koritala and E. N. Frankel, J. Am. Oil Chem. Soc., 1983, 60, 1257.

30. A. Alexakis, N. Lensen and P. Mangeney, Syn. Lett., 1991, 9. 625.

31. P. Boudjouk, B. H. Han, J. R. Jacobsen and B. J. Hauck, J. Chem. Soc., Chem. Commun., 1991, 1424.

32. A. Tai, T. Kikukawa, T. Sugimura, Y. Inoue, T. Osawa and $\mathrm{S}$. Fujii, J. Chem. Soc., Chem. Commun., 1991, 795.

33. G. Olah and A. H. Wu, Synthesis, 1991, 204.

34. D. Goldsmith and J. J. Sorm, Tetrahedron Lett., 1991, 32, 2457.

35. J. Pan, I. Hanna and J. Y. Lallenand, Tetrahedron Lett., 1991, 32, 7543.

36. C. Ranu and M. K. Basu, Tetrahedron Lett., 1991, 32, 3243.

37. B. S. Bhatkhande and S. D. Samant, Ultrason. Sonochem., 1998, $5,7$.

38. A. De Visscher, H. Van Langenhove and P. Van Eeoo, Ultrason. Sonochem., 1997, 4, 145.

39. D. Drijvers, H. V. Langenhove and K. Vervaet, Ultrason. Sonochem., 1998, 5, 13.

40. C. Petrier, Y. Jiang and M.-F. Lamy, Environ. Sci. Technol., 1998, 32, 1316.

41. A. Gaplovsky, M. Gaplovsky, S. Toma and J.-L. Luche,J. Org. Chem., 2000, 65, 8444.

42. M. Meciarova, S. Toma and A. Heribanova, Tetrahedron, 2000, 56, 8561 .

43. K. Rama, E. Nagendra and M. A. Pasha, Indian J. Chem., Sect. $B, 2000,39,563$.
44. J. P. Lorimer, T. J. Mason, M. Plattes and S. S. Phull, Ultrason. Sonochem., 2000, 7, 237.

45. Y. Nagata, M. Nakagawa, H. Okuno, Y. Mizukoshi, B. Yim and Y. Maeda, Ultrason. Sonochem., 2000, 7, 115.

46. L. Rong, Y. Kojima, S. Koda and H. Nomura, Ultrason. Sonochem., 2001, 8, 11 .

47. Y. Mizukoshi, E. Takagi, H. Okuno, R. Oshima, Y. Maeda and Y. Nagata, Ultrason. Sonochem., 2001, 8, 1.

48. R. A. Pethrick, Adv. Sonochem., 1991, 2, 65.

49. H. W. Melville and A. Murray, Trans. Faraday Soc., 1950, 46. 996.

50. D. R. Bassett and A. E. Hamielec,"Emulsion Polymers and Emulsion Polymerization", A. C. S. Symposium Series 165, American Chemical Society, Washington, 1981

51. J. P. Lorimer, T. J. Mason, K. Fiddy, D. Kershaw, R. Groves and D. Dodgson,"Ultrasonics International Conference Proceedings". 1989, 1283.

52. J. J. Leboun and H. Porte in "Comprehensive Polymer Science", eds. J. C. Bevington and G. Allen, Pergamon, New York, 1989 , Vol. 5, Chap. 34.

53. B. H. Han and P. Boudjouk, Tetrahedron Lett., 1981, 22, 3813.

54. K. Ivanov, T. Popov and S. Slavov, Izv. Khim., 1987, 20, 201.

55. T. Popov, D. Klissurski, K. Ivanov and I. Pesheva, Stud. Sur. Sci. Calal., 1987, 31, 191.

56. R. Ranganathan, I. Mathur, N. N. Backshi and J. F. Mathews, Ind. Eng. Prod. Res. Develop., 1973, 12, 155.

57. P. Boudjouk in "Ultrasound : Chemical, Physical and Biological Effects", ed. K. S. Suslick, Verlag Chemie International, 1988, Chap. 5.

58. P. Boudjouk and B. Hauck, "XXV Organosilicon Symposium", Los Angeles, 1992, Abstr. no. 82.

59. T. J. Mason, J. P. Lorimer and D. J. Walton, Ultrasonics, 1990, 28, 333.

60. F. J. Del Campo, A. Neudeck, R. G. Compton and F. Marken,J. Electroanal. Chem., 1999, 477, 71.

61. Y. Masti, M. Homyonfer, A. Gedanken and G. Hodes, Adv. master. (Weinheim), 1999, 11, 1010.

62. Bioprocessing Technology, Technical Insights, U.S.A., 1989.

63. Nippon Shokubai, Kagaku Kogyo EP 0249969 A2/1987.

64. R. Katoh, E. Yanase, H. Yokoi, S. Usuba, Y. Kakudate and S. Fujiwara, Ultrason. Sonochem., 1998, 5, 37.

65. C. Petrier and A. Francony, Wat. Sci. Tech., 1997, 35, 175. 
